\title{
Improving Machine Shop Overall Equipment Effectiveness by Scientific Approach
}

\author{
Senthilkumar $\mathbf{M}^{1}$, Raagul Sakthivel, Ezhilan Gopal \\ \{msk.prod@psgtech.ac.in ${ }^{1}$, rs.prod@psgtech.ac.in ${ }^{2}$ \} \\ Department of Production Engineering, PSG College of Technology, Coimbatore, India
}

\begin{abstract}
Overall Equipment Effectiveness (OEE) is an important parameter in an industrial aspect. It measures how well equipment of lines are utilized when compared to their full probable so as to improve the performance of the industry. In this paper, primary data such as idle time, OEE of individual machines are collected from the industry for the past eight months to know their impact in performance of the industry. After that data for the current month (January 2017) is recorded and OEE is calculated. Then Pareto charts are used to find the most influencing machines and departments that contribute majorly to the OEE loss. Then 5 why analysis is done to find the causes for the current problems and root cause analysis done. After finding the root causes, each of the root causes is attacked to find the solutions. Then suitable solutions are suggested to the industry and with the implemented solutions improved OEE is calculated.
\end{abstract}

Keywords: OEE (Overall Equipment Effectiveness), idle time, 5 why analysis

\section{Introduction}

Overall Equipment Effectiveness (OEE) is a method used in lean manufacturing by any company to determine the effectiveness of the industry and it is usually obtained by product of availability, performance and quality. It measures how well equipment of lines are utilized when compared to their full potential. Bottleneck equipment is closely correlated to the OEE. It affects the OEE and hence the reason to quantify OEE by the company is to make bottleneck equipment work more efficiently. After measuring the OEE and identifying the individual factors that contribute to OEE will give the industry planning team to see where the equipment is losing time. To compute OEE successfully, it requires data which is very accurate and reliable and reflects the real equipment utilization.

$$
\mathrm{OEE}=\mathrm{A} \times \mathrm{P} \times \mathrm{Q}
$$

where, $\mathrm{A}=$ Availability, $\mathrm{P}=$ Performance and $\mathrm{Q}=\mathrm{Quality}$

The work was carried out in a medium scale industry manufacturing automobile components. The company has an average OEE of $45.64 \%$ which is below the targeted OEE. Availability ${ }^{[3]}$ shows how much time the machine was available for production when compared to the actual planned production. It has no unit and it is a fraction and it is represented as percentage. 


$$
\begin{aligned}
& \text { Availability }=\text { Actual Production time / Planned } \\
& \text { production time }
\end{aligned}
$$

Performance efficiency takes the unrecorded downtime into account which contributes to significant losses in production. Performance efficiency is the ratio of the ideal cycle time to actual operating time which is determined by the planning department of the industry.

$$
\text { Performance }=\text { Current Run Rate / Ideal Run Rate }
$$

The quality determines how well the product is reliable that suits the customer's need and the product is rejected if it doesn't conform to their requirements. So, quality is an important contributor for OEE. It takes into account the time gone due to the rejected parts.

$$
\text { Quality }=\text { Good Product } / \text { Total Product }
$$

The paper involves various problems that needs to be rectified. To quantify the problems, necessary data should be collected. After collecting the data, it is analysed and various solutions for the problems are identified. Literature survey helps in finding various methods of data collection for various problems and it helps is identifying a vague solution that can be modified and implemented for a problem that is very similar to problems encountered in literature.

Vijajakumar ${ }^{[10]}$ et al. says planning and scheduling practices influence the enhancement in delivery performance. A study was carried out to improvise the production development and process enhancement in a manufacturing plant. The approach involved reviewing the present methodologies, identifying bottle necks, change overs procedures and reducing workin-progress (WIP). The present study resulted in delivery performance improvement.

Richard Hedman ${ }^{[8]}$ et al. says the mounting digitalization of industry offers means to automatically obtain and examine engineering data. The results can be assimilated to fully apply the potential of automatic data attainment systems and to develop precise OEE measures which will be used to improvise engineering performance.

Puvanarasan $^{[6]}$ et al. gives away the details on development of the OEE of the autoclave procedure through the application of time studies. The paper meaningfully highlights problem in computing the OEE.

Muchiri $\mathrm{P}^{[5]}$ et al. says that the pursuit for improving efficiency in the current global competitive situation has led to a need for thoroughly defined performance-measurement systems. The background complements the variances between concept and practice and makes possible the exhibition of overall production effectiveness that can be tailored with the manufacturers' requirements to increase throughput.

AmirAzizi ${ }^{[1]}$ et al. throws some light that high productivity presentation has a direct association with the equipment efficiency and method control. They evaluated production efficiency by uninterruptedly improvise the equipment efficiency and process control in a manufacturing company. OEE has been projected as the pointer to measure the equipment efficiency. Andersson $\mathrm{C}^{[3]}$ et al. says that the global rapidity of change within the manufacturing industry compels companies to continuously improve making performance. A study shows a opening between these inferences from a theoretical perspective vs. industrial perspective. Connecting this theory-practice gap indicates countless potential for competitiveness and growth in manufacturing. Two productivity measures have been proposed. Chandrajit $\mathrm{P}$ Ahire ${ }^{[4]}$ et al. says that to challenge in global market, no association will bear losses. It takes into account all important procedures of efficiency. Indirectly it 
designates the losses each parameter pays to reduce output. Total 32 hypothesis were considered to establish relation between OEE and FMEA.

Anand S. Relkar ${ }^{[2]}$ et al. pronounces that unceasing obtainability of reliable classy equipment with accuracy is need of the competitive market. Ranteshwar $\operatorname{Singh}^{[7]}$ et al. declares that number of administration procedures has been developed over the years to succeed the manufacturing. Software and hardware have been prepared to measure the OEE. Thomas Dunn ${ }^{[9]}$ et al. designated the manufacturing management practice of OEE.

\section{Problem Statement}

OEE (Overall Equipment Effectiveness) is the typical for measuring manufacturing productivity. It finds the percentage of manufacturing time that is actually productive. An industry needs a maximum OEE so that it is highly productive which leads to increase the profit of the industry eventually. The past data of the shop floor of the industry shows that the average OEE is $45.64 \%$ which is less than the target set by the industry.

\section{Objective}

The objective of the paper is to suggest a suitable proposal to improve the shop floor OEE to maximum level from the existing level by eliminating or minimising the wastages in time and work and also to utilise the machines effectively.

\section{Data Collection}

OEE data is collected for past 8 months as shown in Figure 1 and idle time is collected as it also contributes to OEE loss.

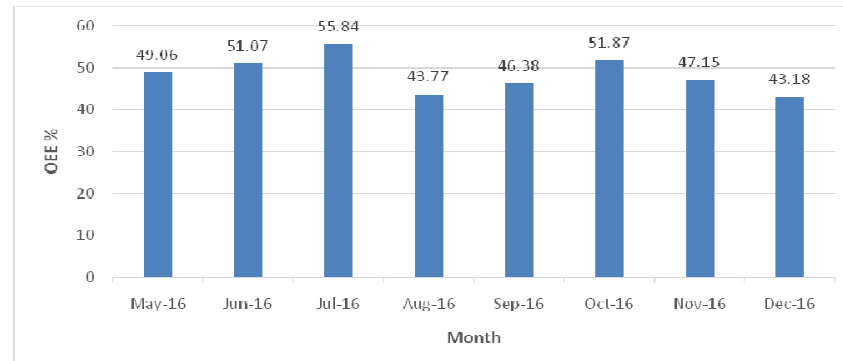

Fig. 1. Past OEE data of the industry 


\section{Data Recording}

The data for idle time is recorded for each machine and the recorded time is then categorised into various departments. Among the various methods ${ }^{[5]}$ listed the stop watch method is chosen for data collection of various machines in the shop floor of the industry.

\begin{tabular}{|l|l|}
\hline \multicolumn{1}{|c|}{$\begin{array}{c}\text { Time Study } \\
\text { Technique }\end{array}$} & \multicolumn{1}{c|}{ Description } \\
\hline Stopwatch & $\begin{array}{l}\text { It is the conventional method that records the time taken by } \\
\text { the work. }\end{array}$ \\
\hline Work sampling & This technique is used to control the time spent. \\
\hline $\begin{array}{l}\text { Predetermine motion } \\
\text { time system (PMTS) }\end{array}$ & $\begin{array}{l}\text { This technique is used in work quantity which advances the } \\
\text { time for a job. }\end{array}$ \\
\hline $\begin{array}{l}\text { Maynard Operation } \\
\text { Sequence Technique } \\
\text { (MOST) }\end{array}$ & $\begin{array}{l}\text { A study of an operation normally where suitable parameter } \\
\text { time values are allocated. }\end{array}$ \\
\hline
\end{tabular}

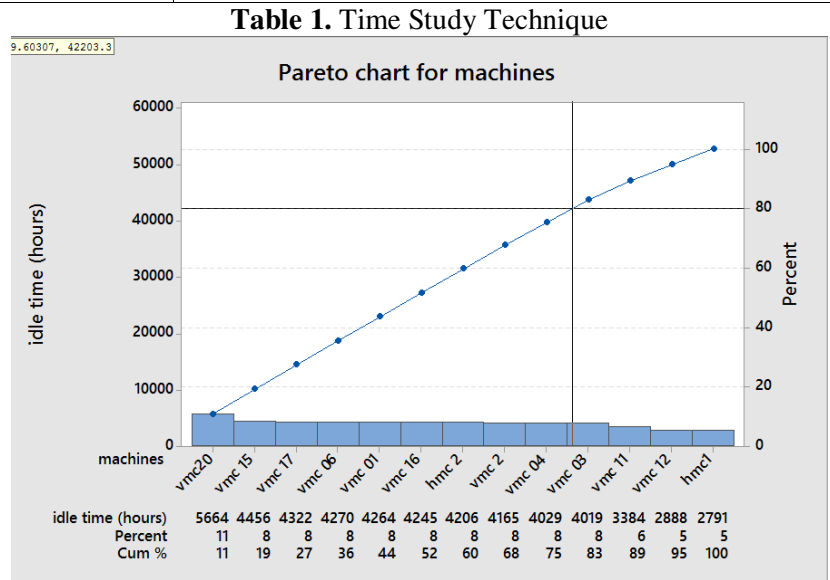

Fig. 2. Pareto chart for machine contribution

The Pareto chart offers that $80 \%$ of the output in a given situation is formed by $20 \%$ of the input. The purpose of the Pareto chart is to highlight the most significant among a set of factors. The figure 2 gives the evident proof that the machine VMC 20 involves in majority of contribution to the idle time and HMC 01 contributes the least. The $80-20$ line on the graph suggests that the most important contributors are, VMC 20,VMC 15, VMC 17, VMC 06, VMC 01, VMC 16, HMC 02, VMC 02, VMC 04. But in this work, the following machines are chosen because the other major contributors lack sufficient data to proceed VMC 20, VMC 15, VMC 17, VMC 16, VMC 01

\begin{tabular}{|l|l|l|}
\hline Machines & \multicolumn{2}{|c|}{ Major Contributing Departments } \\
\hline VMC 01 & $\begin{array}{l}\text { Maintenance, HRD } \\
\text { Development) }\end{array}$ \\
\hline
\end{tabular}




\begin{tabular}{|l|l|}
\hline Machines & \multicolumn{1}{|c|}{ Major Contributing Departments } \\
\hline VMC 15 & HRD, Production and Service sourcing \\
\hline VMC 16 & HRD, Maintenance and Service sourcing \\
\hline VMC 17 & HRD, Production and Service sourcing \\
\hline VMC 20 & HRD, Development and planning \\
\hline
\end{tabular}

Table 2. Contribution of various department

The next step is to use the Pareto charts to find out which factors contribute the OEE loss of each machine that is chosen. The various departments are, Human resource development (HRD),Tool room, Quality, Service sourcing, Maintenance, Production, Planning, Gauge, Development.

In this work, the main problem is the idle time of the machines which in turn contributes to the OEE loss. This idle time is caused due to various reasons of different departments such as HRD, maintenance, Tool room, gauges, quality etc. A basic study of those departments is then made and then the factors contributing to the idle time is then noted as shown in Table 2.

Once the machine with problems is identified, the major idle time causing problems are to be found out. This is done with the help of the Pareto chart to prioritize the departments to which those problems can be accustomed.

Once the departments are sorted out based on their contributions to the idle time, the reasons for that is identified using this technique of asking "why?" For that question, there might be an answer due to which the problem might have occurred in the first place. And further analysis of the reason is done and continued asking "Why?" until the final reason ended up and also accompanied with a self-evident solution.

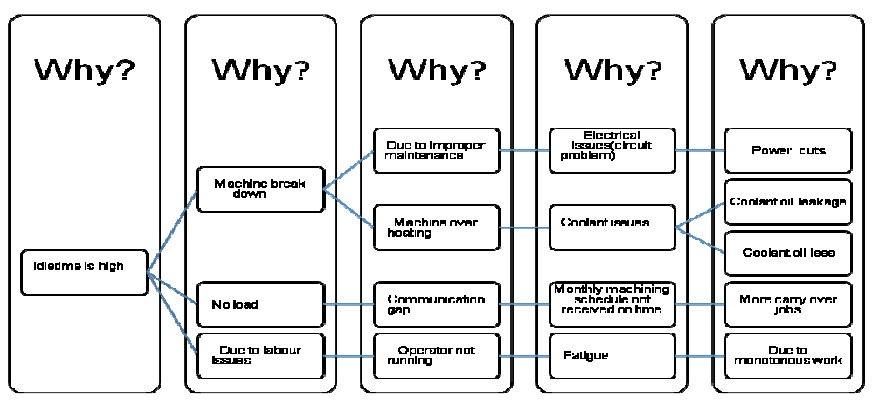

Fig. 3. 5 why analysis for VMC 01

\section{Solution}

From the 5 why analysis problems are found out and various solutions are suggested. 


\section{Scheduling}

In industry scheduling is done manually so they took 1 to 2 days, we suggested them to use Microsoft project software where it will take few hours to do the same work.

Input needed for machine scheduling,

- Jobs

- Cycle time(duration)

- Readiness date

- Priority

Scheduling is done for VMC 1, VMC 6, VMC 15, VMC 17 and VMC 20 using Microsoft Project for February as shown in Figure 4 and Figure 5.

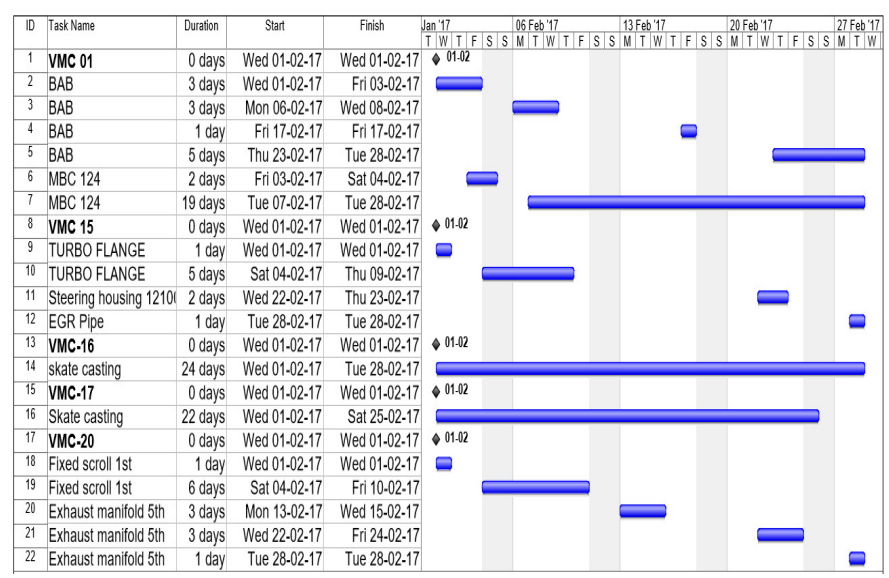

Fig. 4. .Production scheduling for 5 machines in February 2017

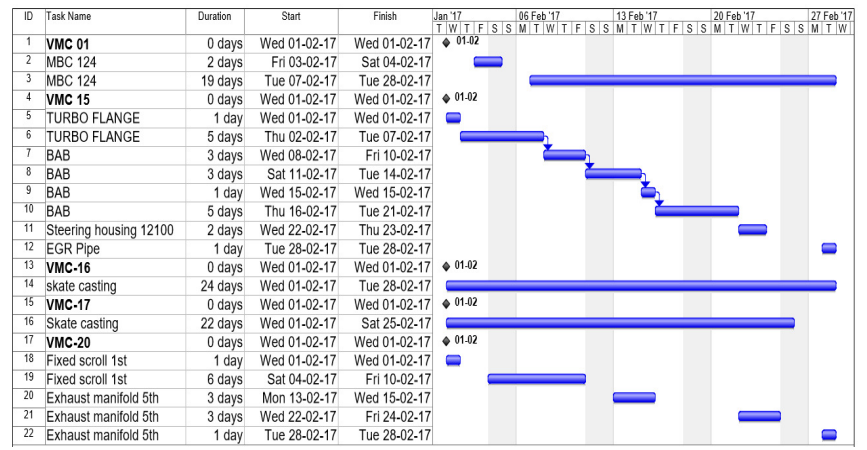

Fig. 5. Production scheduling for 5 machines in February 2017 after proper scheduling 


\section{Labour Zoning}

The labours are not fixed to a machine. Instead they are confined to a region and responsible for the zone's productivity. In the industry we marked two zones in the areas where production influences the OEE significantly.

The machines in the zone 1 are VMC-16 and VMC-17. In both these machines same component "Skate casting" is machined. The problems manifested in the region are labour fatigue and component resting in the machine. The cause for the of labour fatigue is doing monotonous work and cause for component resting in the machine is the inspection of previous component takes more time than machining time. The machining time for skate casting is 8 min with loading and unloading time of average 2.5 minutes. The machining time for skate casting is $8 \mathrm{~min}$ with loading and unloading time of average 2.5 minutes.

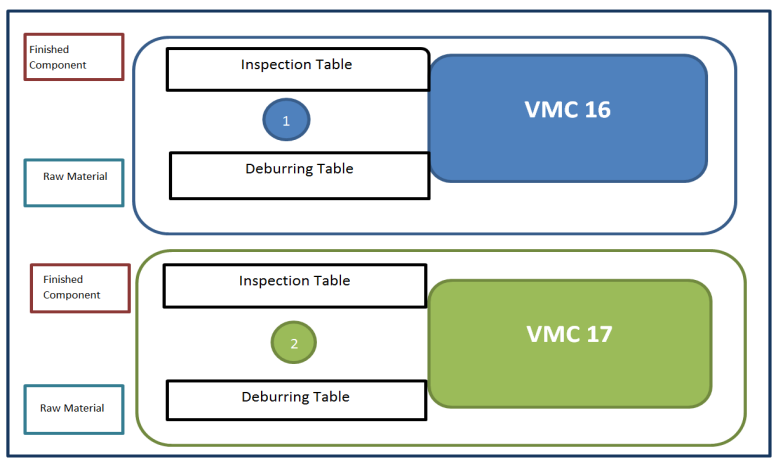

Fig. 6. Before labor zoning

The inspection time is of average 10 minutes. The Figure 5 shows the current practice followed. By implementing zonal labouring, both the labours are responsible for the zone which includes two machines; therefore each machine is looked after by two sets of eye. One labour is assigned with the task of loading and unloading the component and deburring while other one is responsible for inspection.

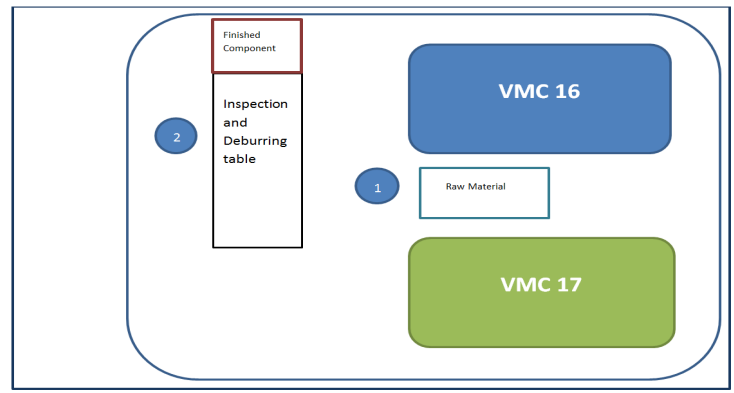

Fig. 7. After labor zoning 
Since one labour is always unloading and loading the component, the component won't rest there inside the machine. Therefore the machine idle time is reduced. They swap jobs at intervals to reduce the monotonicity of work. By implementing this method as shown in Figure 7 there is no need for two set of deburring tools and gauges for inspection.

\section{UPS Implementation}

The machines VMC 01, VMC 06, VMC 15, VMC 17, and VMC 20 are the ones that contribute to the major loss in the shop floor OEE which is found out using the Pareto chart. The blue outline in the layout marks the machines VMC01, VMC 16, VMC 17 in their respective places. Hence this area is the critical one which consists of three of the five machines that needs some attention to improve the OEE.

The red outline marks shown in Figure 8 is the pairing of two CNC machines of the same make to have a common UPS setup instead of getting a separate UPS for each machine thus reducing the initial setup cost. Well the installation of UPS is costly and needs an initial investment which obviously had to be done by the top management. But implementation of this idea in the Shop floor of this industry would make a considerable change in the overall OEE. Thus this implementation helps to reduce the minor stoppages that occur due to the power failure, tool breakages, part rejections due to the possibility of the tool damaging the work piece and the tedious job of setting the tool point to the reference point each and every time when a power failure occurs.

In this case, the all selected machines have very large amount of idle time, of which the power failure contributes to the stoppages to some extent and after when the power returns the operator takes some time to set the spindle to the reference point. 


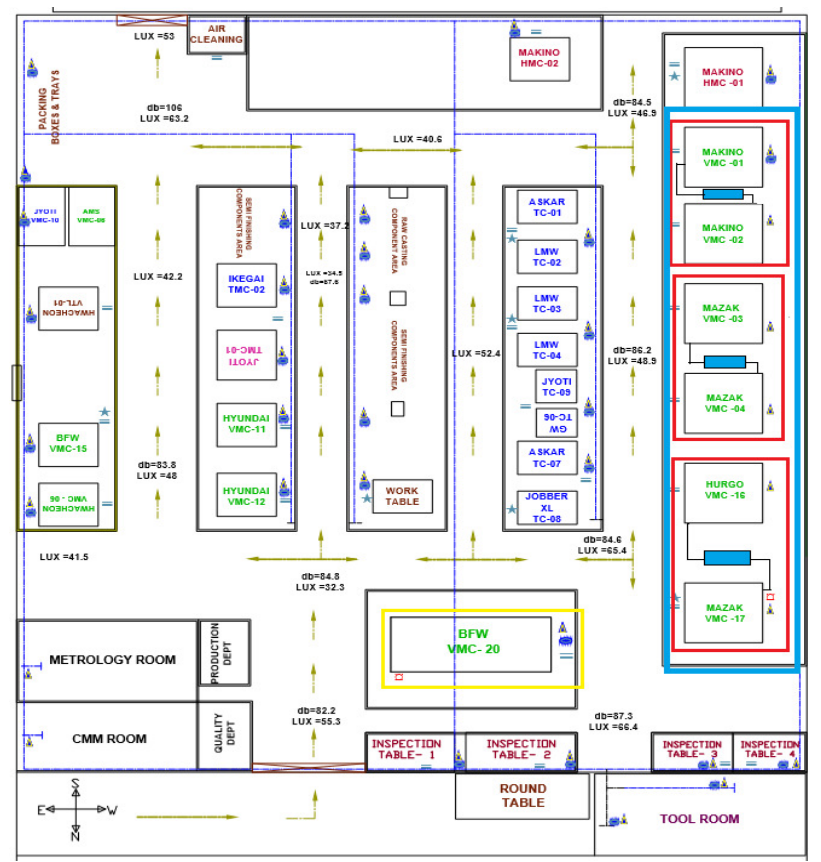

Fig. 8. Shop floor layout with UPS plan

For VMC 16, the cycle time of machining the component named Skate casting is 6 minutes but when a power failure occurs the time to complete the component is more than the expected, this includes the power non available time but it also includes the time required for setting up the spindle to the reference time.

\section{CMM Fixture for Alignment}

After each setting in VMC the first product must be approved by quality department. Quality department will inspect the product for geometric characteristics. They will inspect using CMM, here alignment takes more time so fixture are used. We suggest a standardized fixture rather than having specialized fixture for each products. The standardized fixture consists of seven items

- Fixturing Sets

- Grid Plates

- $\quad$ Fixture Columns

- Positioners

- Supports

- Clamps

- Magnets

CMM clamp sets with 1/4-20 thread size components. Jacks and positioners are used to position and hold work pieces during inspection. Supports and standoffs function as resting 
points to uplift work pieces during inspection. Magnets can also be used to place and grip steel parts for examination. $\mathrm{R} \& \mathrm{R}$ fixture is recommended to install as fixture for CMM inspection.

\section{Setting Checklist}

Table 3 provides necessary items for setting in machine. With this check list in hand idle can be reduced. It tells the availability of various items before starting the setting process.

\begin{tabular}{|c|l|c|c|}
\hline \multirow{2}{*}{$\begin{array}{c}\text { Sl. } \\
\text { NO }\end{array}$} & \multicolumn{1}{|c|}{ Machine Feasibility } & \multicolumn{2}{|c|}{ Available } \\
\cline { 3 - 4 } & & Yes & No \\
\hline 1 & DRAWING & & \\
\hline 2 & CLAMPING JAWS & & \\
\hline 3 & CLAMPING FIXTURE & & \\
\hline 4 & $\begin{array}{l}\text { NO OF TOOL POCKETS } \\
\text { REQUIRED }\end{array}$ & & \\
\hline 5 & FIXTURE HYDRAULIC & & \\
\hline 6 & FIXTURE MANUAL & & \\
\hline 7 & POWER PACK & & \\
\hline 8 & TOOLING LIST & & \\
\hline 9 & PROGRAM & & \\
\hline 10 & GAUGES & & \\
\hline 11 & OPERATOR & & \\
\hline 12 & CMM MACHINE & & \\
\hline 13 & MATERIAL & & \\
\hline 14 & COOLANT OIL & & \\
\hline 15 & FIXTURE TOOLING SPARES & \\
\hline
\end{tabular}

Table 3. Setting checklist for machines

\begin{tabular}{|l|l|}
\hline Machines & \multicolumn{1}{|c|}{ Major Contributing Departments } \\
\hline VMC 01 & $\begin{array}{l}\text { Maintenance, HRD (Human Resource } \\
\text { Development) }\end{array}$ \\
\hline VMC 15 & HRD, Production and Service sourcing \\
\hline VMC 16 & HRD, Maintenance and Service sourcing \\
\hline VMC 17 & HRD, Production and Service sourcing \\
\hline VMC 20 & HRD, Development and planning \\
\hline
\end{tabular}

Table 4. Solution Implementation for machines 
The Table 4 shows various machines and the solutions implemented.

\section{Sample OEE calculation}

In the month of February VMC 01 is queued for more parts and in the case of VMC 15 it has more idle time so the part (Breaker alternator bottom) in VMC 01 is shifted to VMC 15.Before

$$
\begin{aligned}
& \text { Total time: } \quad 576 \text { hours (24days*3shift*8hours) } \\
& \text { Total uptime: } 216 \text { hours (9days*3shift*8hours) }
\end{aligned}
$$

Availability $=$ Total uptime $/$ Total hours

$$
=216 / 576=0.375
$$

Planned parts

Turbo flange: $\quad 118$

Steering housing: $\quad 180$

EGR pipe: $\quad 159$

Actual parts produced

Turbo flange: $\quad 48$

Steering housing: $\quad 58$

EGR pipe: $\quad 138$

Performance $=$ Actual parts produced/Planned parts

$$
=(48 / 118)+(58 / 180)+(138 / 159)=0.6159
$$

Quality = Accepted part $/$ Total part produced

$$
=241 / 244=0.987
$$

$\mathrm{OEE} \quad=\mathrm{A} * \mathrm{P} * \mathrm{Q}$

\begin{tabular}{|c|c|c|c|c|c|}
\hline \multicolumn{6}{|c|}{$\begin{aligned} \text { Availability } & =\text { Total uptime } / \text { Total hours } \\
& =504 / 576=0.875\end{aligned}$} \\
\hline \multirow[t]{5}{*}{ OEE } & \multicolumn{5}{|c|}{$\begin{array}{l}=\mathrm{A} * \mathrm{P} * \mathrm{Q} \\
=0.875 * 0.6159 * 0.987 \\
=0.5311=53.11 \%\end{array}$} \\
\hline & Machine & $\begin{array}{c}\text { OEE } \\
\text { before } \\
\text { impleme } \\
\text { ntation }\end{array}$ & $\begin{array}{c}\text { OEE } \\
\text { after } \\
\text { impleme } \\
\text { ntation }\end{array}$ & $\begin{array}{c}\text { OEE } \\
\text { differenc } \\
\text { e }\end{array}$ & $\begin{array}{l}\text { Percenta } \\
\text { ge } \\
\text { increase } \\
\text { in OEE }\end{array}$ \\
\hline & VMC-01 & $48.22 \%$ & $59.41 \%$ & $11.19 \%$ & $23.21 \%$ \\
\hline & VMC-15 & $22.77 \%$ & $53.11 \%$ & $30.24 \%$ & $30.24 \%$ \\
\hline & VMC-16 & $35.53 \%$ & $48.44 \%$ & $12.91 \%$ & $36.34 \%$ \\
\hline
\end{tabular}

$$
\begin{aligned}
& =0.375 * 0.6159 * 0.987 \\
& =0.227=22.77 \%
\end{aligned}
$$

OEE calculation when proper scheduling implemented.

Total time: $\quad 576$ hours (24days*3shift*8hours)

Total uptime: 504 hours (21days*3shift*8hours) 


\begin{tabular}{|c|c|c|c|c|}
\hline Machine & $\begin{array}{c}\text { OEE } \\
\text { before } \\
\text { impleme } \\
\text { ntation }\end{array}$ & $\begin{array}{c}\text { OEE } \\
\text { after } \\
\text { impleme } \\
\text { ntation }\end{array}$ & $\begin{array}{c}\text { OEE } \\
\text { differenc } \\
\text { e }\end{array}$ & $\begin{array}{c}\text { Percenta } \\
\text { ge } \\
\text { increase } \\
\text { in OEE }\end{array}$ \\
\hline VMC-17 & $19.25 \%$ & $36.21 \%$ & $16.96 \%$ & $88.10 \%$ \\
\hline VMC-20 & $19.91 \%$ & $24.44 \%$ & $4.23 \%$ & $21.25 \%$ \\
\hline
\end{tabular}

Table 5. List of machines and their OEE

\section{Conclusion}

By implementing the solutions that were suggested the OEE of the industry has seen 13.26 percentage increases which is very significant and which can improve the performance of the industry to a greater amount. Improving the OEE of all machines throughout the plant unswervingly affects the performance. This is due to the times of inactive machines are reduced. Screening dependable real-time data of processes meaningfully surges employee efficiency, and enables their work.

- With the implementation of CMM fixture and setting checklist the OEE for VMC 01 is improved from $48.22 \%$ to $59.41 \%$.

- With the implementation of scheduling the OEE for VMC 15 is improved from $22.77 \%$ to $53.11 \%$.

- With the implementation of zonal labouring the OEE for VMC 16 is improved from $35.53 \%$ to $48.44 \%$.

- With the implementation of zonal labouring the OEE for VMC 17 is improved from $19.25 \%$ to $36.21 \%$.

- With the implementation of UPS the OEE for VMC 20 is improved from $19.91 \%$ to $24.44 \%$.

\section{References}

[1]. Amir Azizi: Evaluation Improvement of Production Productivity Performance Using Statistical Process Control, Overall Equipment Effectiveness, And Autonomous Maintenance, 2nd international Materials, Industrial, and Manufacturing Engineering Conference, MIMEC 2015, Procedia manufacturing 2 186-190, 2015.

[2]. J Anand, S Relkar; Nandurkar, K N: Optimising and analysing OEE through Design of Experiments (DOE), Procedia Engineering 38, 2973 - 2980, 2012.

[3]. Andersson, C; Bellgran, M: On the complexity of using performance measures: Enhancing sustained production improvement capability by combining OEE and productivity, Journal of Manufacturing Systems 35, 144-154, 2014.

[4]. Chandrajit, P Ahire; Anand, S Relkar: Correlating Failure mode effect analysis and OEE, Procedia Engineering 38, 3482 - 3486, 2012.

[5]. Muchiri, P; Pintelon, L: Performance measurement using overall equipment effectiveness (OEE) International Journal of Production Research, 46:13, 3517-3535, 2008.

[6]. Puvanasvaran, A.P; Mei, C.Z; Alagendran, V.A: Overall Equipment Efficiency Improvement Using Time Study in an Aerospace Industry, The Malaysian International Tribology Conference, Procedia Engineering 68, 271-277, 2013.

[7]. Rantheshwar Singh; Dhaval, B Shah; Ashish, M Gohil and Milesh, H Shah: OEE calculation Automation through hardware and software, Procedia Engineering 51, $579-584,2013$. 
[8]. Richard Hedman; MukundSubramaniyan and Peter Almström: Analysis of critical factors for automatic measurement of OEE, 49th CIRP Conference on Manufacturing Systems, Procedia CIRP 57, $128-133,2016$.

[9]. Thomas Dunn: 8 - OEE Effectiveness, Materials, Machinery, and Techniques 2014, Pages 77-85, 2014.

[10]. Vijaya Kumar, S; Mani, VGS and Devraj, N: Production planning and process improvement in an impeller manufacturing using scheduling and OEE techniques, Procedia Materials Science, 5, 1710
$-$
1715 ,
2014. 